\title{
Climate change adaptation among poultry farmers: evidence from Nigeria
}

\author{
Lenis Saweda O. Liverpool-Tasie ${ }^{1}$ (D) $\cdot$ Awa Sanou $^{2}$ • Justice A. Tambo ${ }^{3}$
}

Received: 1 October 2018 /Accepted: 2 October 2019/Published online: 14 November 2019

(C) The Author(s) 2019

\begin{abstract}
Though climate events pose increasing challenges for crop and animal production in Africa, most climate adaptation studies focus on staple food crops. Few studies have examined climate adaptation for livestock with even fewer looking at small animals such as poultry. Heat stress associated with climate change is a severe challenge to poultry farmers due to its negative effect on chicken growth and productivity. As poultry plays an important food security role across Africa (being a source of livelihood and an important source of animal protein), understanding how farmers deal with the realities of poultry production due to climate change is critical. This study explores the level and determinants of the adoption of climate change adaptation strategies among poultry farmers in Nigeria. A multivariate probit analysis (which allows for the possibility that the decision to adopt various practices are jointly made) reveals that while poultry farmers are adapting to climate change, there is a clear heterogeneity of adaptation strategies at different production scales. Small farms tend to invest in traditional strategies such as the stocking of local breeds while medium and large farms adopt modern technologies such as air and water ventilation as well as the use of low energy bulbs that emit less heat. Our study finds that farmers who have experienced heat-related losses are more likely to adopt modern practices and more likely to adopt multiple adaptation strategies concurrently.
\end{abstract}

Keywords Climate change $\cdot$ Adaptation $\cdot$ Poultry farmers $\cdot$ Nigeria

\section{Introduction}

Climate change adaptation is extremely important in Nigeria. As the country strives to meet the food consumption needs of its rapidly growing population, agriculture in the country (as in the

Electronic supplementary material The online version of this article (https://doi.org/10.1007/s10584-01902574-8) contains supplementary material, which is available to authorized users.

Lenis Saweda O. Liverpool-Tasie

lliverp@msu.edu

Extended author information available on the last page of the article 
rest of sub-Saharan Africa) is expected to be among the hardest hit by climate change (Parry et al. 2004; Mendelsohn and Massetti 2017). Global climate and crop production models forecast lower yields for staple crops in West Africa as a result of climate change (Jones and Thornton 2009; Sonneveld et al. 2012). Climate impacts will be even more pronounced in arid and semi-arid areas where increased drought frequencies are expected to reduce vegetation cover and livestock numbers, and higher temperatures to cause an increase in the demand of already scarce water sources for livestock (Thornton et al. 2009; Debela et al. 2015; Ayanlade et al. 2017; Ou and Mendelsohn 2017). For Nigeria, climate projections predict a rise in temperature of 1.1 to $2.5^{\circ} \mathrm{C}$ by 2060 and an increase in the number of extreme heat days to 260 by 2100 compared with 10 days in 1990 (USAID 2019). Studies have also documented increased variability in rainfall, dry spells during the rainy seasons, and increased irregularity in the amount of precipitation once the rainy season sets in (Adejuwon and Odekunle 2006; Ayanlade et al. 2017; Abatan et al. 2018).

Though these climate events pose increasing challenges for crop and animal production, most climate change impact studies focus on staple food crops (Seo and Mendelsohn 2008; Ayanlade et al. 2017; Hitayezu et al. 2017; Mulenga et al. 2017; Sesmero et al. 2017; Ayanlade et al. 2018). There are very limited studies that have examined the effects of climate change on African livestock, and those few tend to focus on large livestock such as beef cattle (Silvestri et al. 2012; Zampaligré et al. 2014; Debela et al. 2015). An extensive review of the literature revealed no published studies on climate change adaptation by poultry farmers in Africa despite their sensitivity to climate change and their significant contribution to livelihood in many African countries (Nyoni et al. 2019). Consequently, this study contributes to filling this gap by exploring climate change adaptation among poultry farmers in Nigeria, one of Africa's largest economies and expected to be among the top three most populated countries worldwide by 2050 (United Nations 2017).

Africa has been identified as a key driver of global meat consumption growth in the next few decades and for which domestic production must play an important role (The Economist 2019). With its high rate of urbanization and increasing incomes, Nigeria's increasing demand for animal proteins has been accompanied by a rapid domestic supply response. Between 1980 and 2008, the country experienced a two-fold increase in its poultry production and the share of maize allocated to animal feed increased in volume by 300\% between 2003 and 2015 (Liverpool-Tasie et al. 2017). The expansion of the poultry industry in Nigeria has been attributed to the low cost of production and low barriers to entry for poultry production compared with other livestock products (Heise et al. 2015). The recent rapid growth of the poultry industry has translated into about 85 million Nigerians being involved in poultry production (many on a small or medium scale) and over 14 million people benefitting from employment in the increasingly commercialized sector (PAN 2017). Currently, the sector serves as an important source of employment and an affordable animal protein (particularly from eggs) for the country's large and growing population that is increasing its consumption of poultry products (Zhou and Staatz 2016; Liverpool-Tasie et al. 2017; United Nations 2017).

Though not as visible in the literature, poultry and other livestock farmers are already experiencing the adverse effects of climate change. ${ }^{1}$ For example, studies have demonstrated that pastoralists and livestock farmers across Africa have associated changes in temperature and rainfall patterns with reduced feed sources, increased animal mortality, lower herd sizes,

\footnotetext{
${ }^{1}$ With no studies found on climate adaptation among poultry farmers specifically, we focus on the literature on adaptation for livestock more broadly.
} 
reduced water sources in the dry season, decreased animal productivity, and the occurrence of new animal diseases (Silvestri et al. 2012; Zampaligré et al. 2014; Debela et al. 2015; Ayanlade et al. 2017). Though largely unstudied in the climate adaptation literature in Africa, increased dryspells and temperatures in the region can affect poultry production directly and indirectly. Increased temperature and heat stress have been linked to losses in poultry production from death, low egg production (quantity and quality), and reduced growth rate in intensive poultry farming systems commonly found in Africa and Asia (Gous 2010; Gregory 2010; Bhadauria et al. 2014). When faced with heat stress, chickens reduce their feed intake to regulate their internal temperature which affects their growth and productivity (Nyoni et al. 2019). Climate change affects poultry (and other livestock) production indirectly because of its effect on maize yields. Maize is a key ingredient in poultry feed and lower maize yields due to climate change affects the availability and price of feed and the profitability of the poultry enterprise.

To sustain the growth of this important economic sector in the face of climate change, it is important to understand how poultry farmers are responding to climate events and their investment in adaptation strategies. The decision to adopt a strategy depends on a farmer's knowledge of and confidence in the benefits of a strategy, the scale of his operation, the likely risk associated with not adapting and his financial ability to bear the cost associated with the strategy (Ayanlade et al. 2018; Massetti and Mendelsohn 2018; Seo and Mendelsohn 2008). Farmers' perception about climate change and their experiences of loss due to climate factors are also likely to affect their adoption of adaptation strategies (Woods et al. 2017; Zamasiya et al. 2017).

Farmers' perceptions of climate change (and climate change impact on adaptation) have been captured in the literature for crop farmers (Tambo and Abdoulaye 2013; Debela et al. 2015; Mulenga et al. 2017; Woods et al. 2017; Zamasiya et al. 2017). However, little is known about the effect of farmer experiences with climate-based losses on the adoption of adaptation strategies in livestock production systems, and more specifically in poultry farming. Consequently, this study explicitly incorporates farmers' experiences with loss due to extreme weather on their adaptation and choice of adaptation strategy. We use data from a sample of small, medium, and large poultry farmers to explore the drivers of climate change adaptation and the heterogeneity of such adaptation practices by poultry farmers at different production commercialization levels.

This study makes several contributions to the literature. First, this is the first study the authors are aware of to explore climate change adaptation among poultry farmers in Nigeria or Africa. Second, this is also the first study to explore farmer adaptation to climate change among poultry farmers with an explicit focus on their experiences with climate induced losses and not just farmer exposure to extreme weather or climate events. Third, this study explicitly distinguishes between the scales of operation of poultry farms to distinguish between poultry farms at different levels of commercialization. Understanding such heterogeneity is important for policy makers and development practitioners trying to support the sustained growth of this dynamic sector with programs specifically targeted at different kinds of poultry farmers. As food systems across Africa transform, the importance of poultry products as an affordable animal protein and source of economic livelihood is expected to grow (The Economist 2019). Thus, the results of this paper are relevant to the global food security and climate change debate.

The remainder of the paper is organized as follows: Section 2 describes the data used and the empirical approach. Section 3 presents the study results, and Section 4 is the conclusion. 


\section{Materials and methods}

\subsection{Data}

This study relies on poultry farmers' survey conducted in the main poultry producing local government areas $\left(\mathrm{LGAs}^{2}\right.$ ) of two major poultry producing states (Kaduna and Oyo) in Nigeria between August and September 2017 (see Fig. 1). The two study locations were selected because they are the main poultry production zones serving consumption zones in Northern and Southern Nigeria, respectively. While both states face some similar climate events (particularly heat stress), the two states represent different cultural and agroecological conditions in Nigeria. Kaduna is the capital city of Kaduna State, located in the northwest Nigeria. Kaduna City is a trade center and a major transportation hub for the surrounding agricultural areas with its rail and road junctions. It is also an industrial center of Northern Nigeria, manufacturing products such as textiles, machinery, steel, aluminum, petroleum products, and bearings. It is home to several large farms and grain markets with significant poultry, cattle and other livestock production. It is found in the Sudan savanna agroecological zone of Nigeria that typically has an annual average rainfall of about 700-1100 mm with a prolonged dry season of about 6-9 months (Aremu et al. 2017). Ibadan, which is in south-west Nigeria, is the capital city of Oyo State and is located about $145 \mathrm{~km}$ north-east of Lagos, the most populous city in Nigeria (UPA 2007). Ibadan is the largest Nigerian metropolis in terms of geographical area and the third largest metropolis in terms of population, after Lagos and Kano. Ibadan is located in the tropical rainforest agroecological zone with mean temperature and rainfall of about $26.5^{\circ} \mathrm{C}$ and $1489 \mathrm{~mm}$, respectively. This agroecological zone has more of a bimodal rainfall pattern and less of a clear distinction between wet and dry seasons (Aremu et al. 2017). The predominant crops produced in Ibadan are staple food - cassava, maize, and vegetables such as Chinese spinach, okra, aubergine, cucumber, tomatoes, and pepper. Ibadan has experienced a rapid growth in poultry and aquaculture in the last decade (Sahel Capital 2015; World Fish 2018).

The sampling strategy adopted in both locations was purposive. For smallholder poultry farms, we selected the two local government areas (LGAs) with the largest production of chickens from the 11 LGAs that constitute the greater Ibadan Area (and feed the Lagos food shed in southern Nigeria) and the 4 LGAs that constitute the greater Kaduna City Area. ${ }^{3}$ Next, the wards within each selected LGA were stratified into low, medium, and high production areas. Focusing on the medium and high production wards within each LGA, the households were categorized into four groups according to the number of birds held zero to less than or equal to five birds, six to less than or equal to 30 birds, 31 to less than or equal to 100 birds, and more than 100 birds.

The final sample for the household farms consists of a random selection of 150 households from each of the four categories mentioned above. For non-household farms, all the farms identified in the 11 (4) LGAs in Ibadan (Kaduna) were listed and subsequently included in the sample. Given that there were non-responses, the analysis in this paper includes 1301 poultry farms across 9 LGAs; 677 farmers in Oyo state and 624 in Kaduna state. While this sample is not representative of poultry producers in Nigeria, it is representative of the main poultry

\footnotetext{
${ }^{2}$ LGAs are the equivalent of counties in the USA and the third administrative level of government in Nigeria.

${ }^{3}$ Local government areas are the third tier of government administration in Nigeria, similar to a county in the USA.
} 


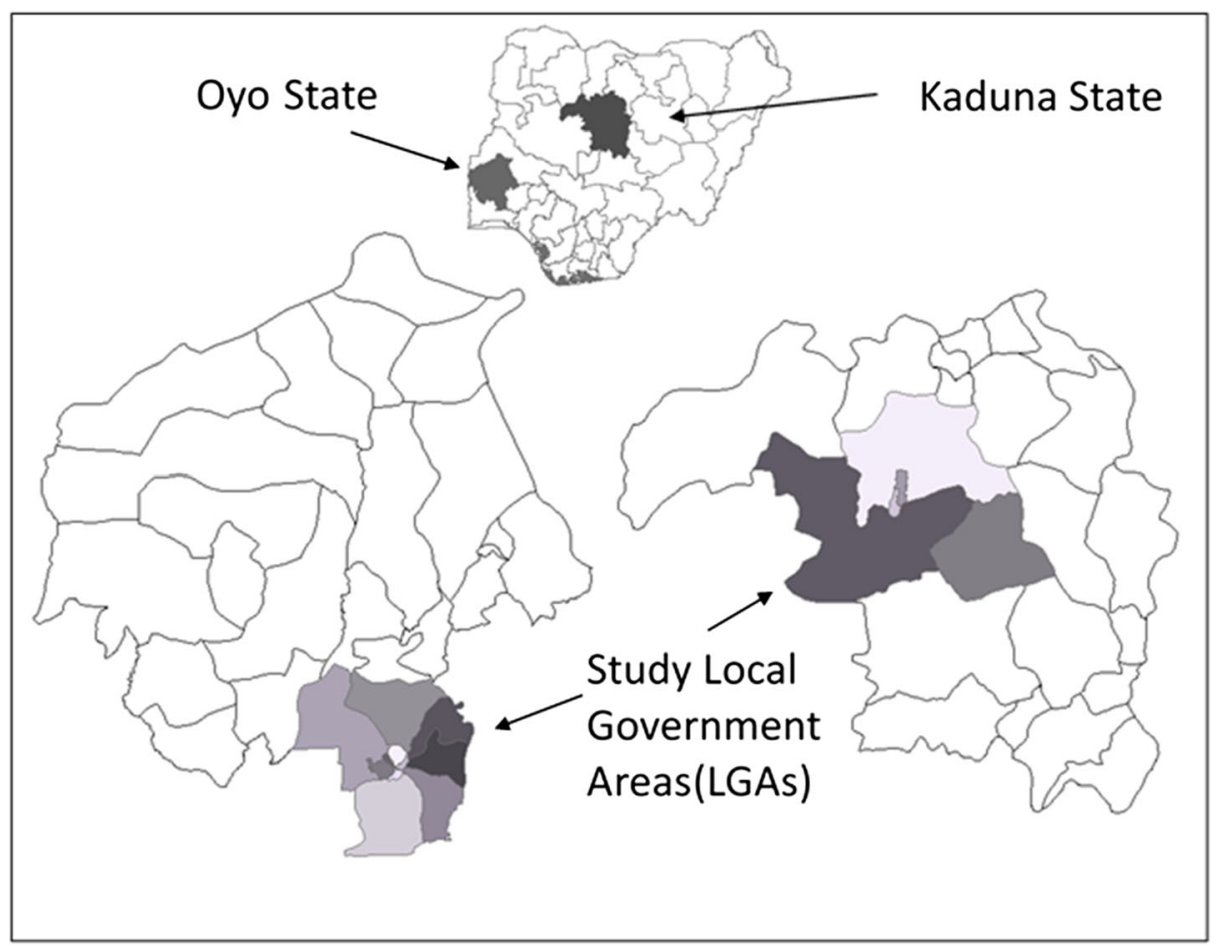

Fig. 1 Map of study area

producing local government areas in both states. The survey gathered socio-demographic information on poultry farmers and the characteristics of their farms including management and marketing practices. We also collected information on farmers' perceptions of climate change and their adaptation strategies in response to an increase in the duration of heat stress now compared with 20-30 years ago.

\subsection{Empirical strategy}

The decision to adopt a specific adaption strategy depends on an unobservable latent variable (farmer's utility), which is determined by one or more explanatory variables such as their experience with poultry farming, their knowledge about the practices, their scale of operation etc. The higher the utility, the greater the probability of adoption. Although we do not observe the latent variable $\boldsymbol{Y}_{i m}^{*}$ for each strategy $m$ that farmer $i$ can adopt, we can quantify the ultimate decision in terms of the farmer adopting or not adopting with a variable $\boldsymbol{Y}_{\boldsymbol{i m}}$. This is a binary decision which can be estimated using a probit model where the response probability depends on a set of parameters which are a function of the standard normal cumulative distribution. In our study, we are considering 8 different strategies. Thus we model the farmer's adoption decision using the following 8 equation multivariate probit models in line with Cappellari and Jenkins (2003)

$$
Y_{i m}^{*}=\left[\beta_{m}^{\prime} X_{i m}+\varepsilon_{i m}\right] ; m=1,2, \ldots, 8
$$


$\boldsymbol{Y}_{\boldsymbol{i m}}=1$ if $\boldsymbol{Y}_{\boldsymbol{i m}}^{*}>0$ and 0 otherwise, $\boldsymbol{\varepsilon}_{\boldsymbol{i m}}, m=1, \ldots, 8$, are error terms distributed as multivariate normal, each with a mean of zero, and variance-covariance matrix $V$, where $V$ has a value of 1 on the leading diagonal and correlations $\rho_{\mathrm{jk}}=\rho_{\mathrm{kj}}$ as off-diagonal elements.

$\boldsymbol{X}_{\boldsymbol{i} \boldsymbol{m}}$ is the vector of explanatory variables included in the model. $\boldsymbol{\beta}_{\boldsymbol{m}}$ is a vector of parameters to be estimated. We evaluate the multivariate probit model using GewekeHajivassiliou-Keane (GHK) smooth recursive conditioning simulator. For each observation, a likelihood contribution is calculated for each replication, and the simulated likelihood contribution is the average of the values derived from all the replications. The simulated likelihood function for the sample as a whole is then maximized using maximum likelihood. One advantage of the multivariate probit model is that it allows for possibility that the decisions on the adoption of any particular adaptation strategy could be jointly made with the decision to adopt other practices. It also enables us to determine if certain adaptation practices are considered as substitutes or complements to each other.

Next, we model the extent of adoption of the adaptation strategies. Adopting multiple strategies (particularly where they are complementary to each other or each strategy plays a distinct role) is likely to increase farm resilience. However, they have cost implications, and thus a farmer's ability to adopt multiple strategies will depend on their level of exposure and access to capital. Here we define a new outcome variable equal to the number of strategies adopted by farmer i. The outcome variable now is a count variable which takes on the following nonnegative integer values $\{0,1,2,3,4,5,6,7,8\}$. We estimate the model using the Poisson estimation strategy. Because adaptation practices in our study context could be substitutes or complements, the adoption of more practices indicates higher intensity of adoption, but more practices do not necessarily mean that adaptation is better. In this situation, the assumption of the Poisson model is less restrictive than that of the ordered probit or logit models where the outcome variable is conceptually appropriately ordered (Fisher and Snapp 2014; Bahinipati 2015).

Furthermore, the underlying Poisson distribution has the advantage of only being determined by its mean (Wooldridge 2010). The probability that the outcome variable $y$ equals the number of adaptation strategies adopted can be modeled as follows:

$$
P(y \mid \boldsymbol{x})=\exp [-\mu(\boldsymbol{x})][\mu(\boldsymbol{x})]^{y} / y ! ; y=0,1,2,3,4,5,6,7,8
$$

where $y$ ! is $y$ factorial, $\mu(\boldsymbol{x})=\exp (\boldsymbol{x} \boldsymbol{\beta})$, and $\boldsymbol{x}$ is a vector of explanatory variables included in the model. $\boldsymbol{\beta}$ is a vector of parameters to be estimated. .

As a robustness check to confirm that our results are not driven by the selection of the estimation strategy, we also express the extent of adoption as the share of the total number of strategies that a farmer adopts. The outcome variable $(y)$ here is the number of strategies adopted out of a total of eight strategies. We use a fractional probit model and model the conditional mean as a probit function:

$$
E(y \mid \boldsymbol{x})=\Phi(\boldsymbol{x} \boldsymbol{\beta})
$$

where $\Phi$ is the normal distribution and $\boldsymbol{x}$ is a vector of explanatory variables included in the model. $\boldsymbol{\beta}$ is a vector of parameters to be estimated.

A variance inflation factor (VIF) was computed for each explanatory variable to check for multicollinearity. All the explanatory variables had VIFs of less than 10 (see Online Resource 1) with an average value of 2.38 , suggesting that multicollinearity is not a problem in our 
regressions. Furthermore, we report robust standard errors to correct for possible heteroskedasticity.

\section{Results and discussion}

\subsection{Descriptive statistics}

The average poultry farmer in our sample is 53 years old, though medium and large farms tend to be owned by slightly younger farmers, between 40 and 48 years old (Table 1). Backyard poultry farming seems to be the domain of women, as about $60 \%$ of small poultry farmers are women. While more of the medium and large farms tend to be managed by men, there is still significant female participation. This is consistent with Liverpool-Tasie et al. (2017) that documented active engagement of women in this livestock subsector in Nigeria. Poultry farmers with large farms have been in the business for an average of 8 years while those in medium farms for an average of 7 years. Contrary to the idea that farmers with medium and large farms will be more likely to specialize, we find that over $60 \%$ of medium and large poultry farmers have other occupations beside farming. One plausible explanation for this is that many medium and large farm owners maintain other jobs to supplement their income and

Table 1 Descriptive statistics of key variables

\begin{tabular}{|c|c|c|c|c|}
\hline & $\begin{array}{l}\text { All } \\
\text { Mean }\end{array}$ & Small $(\mathrm{T} 1)^{\mathrm{a}}$ & Medium (T2) & Large (T3) \\
\hline Age (years) & 53.02 & 53.66 & 41.41 & 44.69 \\
\hline Male $(0 / 1)$ & 0.39 & 0.37 & 0.69 & 0.57 \\
\hline Education $(0 / 1)$ & 0.68 & 0.67 & 0.87 & 0.95 \\
\hline Number of years farming & 5.91 & 5.83 & 7.01 & 8.05 \\
\hline Job other than farmer $(0 / 1)$ & 0.64 & 0.63 & 0.83 & 0.67 \\
\hline Own freezer $(0 / 1)$ & 0.01 & 0.01 & 0.06 & 0.05 \\
\hline Own truck $(0 / 1)$ & 0.00 & 0.00 & 0.03 & 0.18 \\
\hline Received training in chicken production from gov $(0 / 1)$ & 0.02 & 0.02 & 0.11 & 0.10 \\
\hline Received training in chicken production from private $(0 / 1)$ & 0.02 & 0.02 & 0.10 & 0.22 \\
\hline Received training in chicken production $(0 / 1)$ & 0.05 & 0.04 & 0.27 & 0.39 \\
\hline Member of association $(0 / 1)$ & 0.01 & 0.00 & 0.17 & 0.31 \\
\hline Poultry farm size (number of birds) & 108.80 & 15.20 & 438.73 & 4725.08 \\
\hline Record keeping $(0 / 1)$ & 0.10 & 0.08 & 0.55 & 0.79 \\
\hline Own borehole $(0 / 1)$ & 0.27 & 0.26 & 0.29 & 0.58 \\
\hline Own well $(0 / 1)$ & 0.54 & 0.54 & 0.65 & 0.61 \\
\hline Own borehole or well $(0 / 1)$ & 0.58 & 0.57 & 0.75 & 0.95 \\
\hline Experienced loss from weather event $(0 / 1)$ & 0.10 & 0.10 & 0.18 & 0.19 \\
\hline Buy feed $(0 / 1)$ & 0.15 & 0.12 & 0.57 & 0.70 \\
\hline Number of observations & 1301 & 449 & 428 & 424 \\
\hline
\end{tabular}

a $\mathrm{T} 1, \mathrm{~T} 2$, and $\mathrm{T} 3$ refer to farm size (bird holding) terciles where $\mathrm{T} 1=0-100$ birds, $\mathrm{T} 2=101=1000$ birds, and $\mathrm{T} 3=>1000$ birds referred to as small, medium, and large scale farms in this study. While we recognize that this categorization might be different from that in many developed countries, it is consistent with the reality of the emerging poultry industry in Nigeria. The descriptive statistics have been weighted to be representative of the study regions 
enable them to bear the financial burden of running such farms and the shocks inherent in the subsector. Membership in a poultry association is more prominent among large farms.

Asset distribution varies across farm types. While nearly $20 \%$ of large poultry farms own a truck, this is an asset owned by only $3 \%$ of medium farms. This clearly reflects different transportation needs based on the size of the farm. Many poultry farms in Nigeria own wells or boreholes. This is not surprising given the poor water supply system in the country. While many more farms own wells compared with boreholes (expected as the costs of drilling boreholes is significantly higher than for wells), over $95 \%$ of large farms have their own independent water supply.

Receiving training and keeping financial records are largely restricted to medium and largescale farms. Only about $10 \%$ of small farms keep financial records compared with 55 and $79 \%$ for medium and large farms, respectively. While about $30 \%$ of medium and large farms got some training on poultry production, only $4 \%$ of small farms did. A key difference between medium and large farms is that the latter tend to have more access to private training $(22 \%$ compared with $10 \%$ for medium farms). This implies that the poultry sector is fueling an increased demand for private extension services. While investment in feed is more prevalent among larger farms, we see evidence of their use among small farms. Between 60 and $70 \%$ of large and medium farms buy feed compared with $15 \%$ of small farmers.

\subsection{Climate change adaptation strategies of poultry farmers}

In this section, we present the climate change adaptation strategies implemented by the 1301 Nigeria poultry farmers in our sample. About $68 \%$ of poultry farmers in our sample believe that the temperature has increased significantly. Almost $50 \%$ of all poultry farmers reported that they had observed an increase in the length of heat stress in their state. Consequently, this study considers a set of eight adaptation strategies that poultry farmers are recommended to use in response to heat stress. ${ }^{4}$ These strategies include air ventilation, water ventilation, engagement in fish farming, litter spreading and decaking in chicken houses, the use of energy efficient bulbs, and the use of vitamins and medicines for the birds. These strategies are relatively novel in the context of the study because they have emerged as a practice in recent years. Additionally, we incorporate traditional practices which we define to include early stocking of birds, higher frequency of litter change during the heat period, and keeping local breeds of birds.

In this study, air ventilation refers to the use of fans, air conditioning, or desert coolers in chicken coops. This strategy can regulate heat levels in poultry farms but also helps with the evacuation of smells that emanate from poultry waste. Water ventilation has functions similar to those of air ventilation. For instance, the use of water sprinklers or cooling pads for the birds enables better internal thermoregulation. Evidence gathered during focus group discussions suggest that the farmers use these different types of ventilation methods to reduce the incidence of heat stress as well as reduce mortality rates and improve feed intake and conversion rates for their birds.

\footnotetext{
${ }^{4}$ The list of selected strategies was drawn up based on interactions with various actors along the poultry value chain in Nigeria including poultry farmers, veterinary doctors, animal scientists, researchers, and poultry input dealers. All of these practices can be considered as climate change adaptation strategies because according to the IPCC (2007), adaptation can be autonomous (i.e., adaptation happens without deliberate policy decisions) or planned (i.e., adaptation resulting from deliberate interventions).
} 
Engagement in an integrated farming system comprised of poultry and fish farms is another adaptation strategy. This has the advantage of providing a cooler environment for the birds when the temperatures get warmer. Poultry farmers who are also owners of fish farms shared that the water of the pond cools the environment for the birds, and it also gives them access to water. This is useful because a cooler environment is conducive to better-feed conversion ratios (and growth) and increases egg production.

The use of energy efficient bulbs in chicken houses also promotes a cooler environment on the farm by emitting less heat. Anecdotal evidence suggests that many farmers adopt efficient bulbs over conventional ones with the aim to reduce the exposure of birds to heat but also to lower the cost of energy on their farms. Warmer temperatures are associated with heat stresses for the birds but also a higher incidence of diseases. Thus, farmers also use vitamins to prevent heat strokes in the birds and medicines to prevent diseases.

The traditional adaptation strategies are known to farmers as good practices with low cost implications that can improve productivity on their farm but also help them respond to a warmer climate. Early stocking is the process of breeding day old chicks (layers) in October such that they can start laying eggs in January/February before it gets too hot in March/April. Several poultry farmers adopt this strategy to allow their layers to benefit from the low temperatures during the laying period. This improves the number of eggs they lay per day. In addition, the frequency of litter change and cleaning of pens during the heat period is negatively correlated with the buildup of heat on the farms. In effect, it prevents the unnecessary accumulation of chicken waste which in turn produces methane. This is because the accumulation of methane exposes birds to warmer temperatures in the pens. In the Nigerian context, the Shika brown is a local breed of bird that is heat tolerant. Contrary to what it name suggests, the Shika brown has light colored feathers which reflect heat. Developed by the National Animal Production Research Institute (NAPRI) at Ahmadu Bello University, the Shika brown is known for its large and brown eggs, and high feed conversion efficiency (Dessie and Getachew 2016). In view of the warmer temperatures that farmers are experiencing, the Shika Brown has the added bonuses of being highly adaptable to the heat and to diseases.

The adoption of the various adaptation strategies in Nigeria varies significantly across farms of different sizes. While about $20 \%$ of medium and large farms have both poultry and fish farms on the same premise, only $1 \%$ of small farms reported the same. For water ventilation as well, adoption rates by the smallest farmers is less than $1 \%$. While $15 \%$ of large farms adopt water ventilation practices, only about $2 \%$ of medium farms adopt this practice. This reflects differences in the strategies that are being adopted across farm sizes. Though the adoption of air ventilation practices is generally higher than water ventilation, adoption is largely restricted to larger farms. Sixteen percent of the large farms use air ventilation alongside $6 \%$ of medium farms in both states. The adoption rate for energy efficient bulbs is relatively higher than air and water ventilation but varies across farm type. It is also largely adopted by larger farms, at more than $30 \%$, compared with $16 \%$ for medium farms, and only $7 \%$ for small farms. Investments in medicines and vitamins increase with farm size but many more farmers buy vitamins. Overall, close to $30 \%$ of farmers buy vitamins for their birds but this is driven by medium and large farms. The same holds true for medicines because the $13 \%$ of farms which buy medicines is disaggregated by $10 \%$ of small farms, $54 \%$ of medium farms, and $75 \%$ of large farms.

As noted earlier, our traditional strategies include early stocking, frequency of litter change, and keeping local breeds. Overall about $70 \%$ of all farms implement these practices. However, 
the number of farms which adopt them decreases as the size of the farm increases. In effect, $72 \%$ of small farms commonly revert to these practices, but only $40 \%$ of medium and large farm do the same. A look at each of the strategies that make up the traditional strategies presents a similar picture. The practice of early stocking though more popular among medium and large farms is still only practiced by about $5 \%$ of medium and large farms in both states. The use of litter spreading or decaking of the chicken houses also varies significantly across farm types. Among the practices where we do see significant participation of small poultry farmers is in the frequent change in litter and the use of local breed. For the frequency of litter change, this is $60 \%$ of small farms compared with only about half of medium and large farms (30-35\%). Changing the litter is considered a labor-intensive practice, and this might reflect the willingness of small farms to adopt adaptation strategies that might be more labor intensive but less costly. As for keeping local birds, it is practiced by $65 \%$ of small farms, $16 \%$ of medium farms, but only $4 \%$ of large farms. Interaction with small farms revealed that they prefer local breeds because they are low maintenance and can sustain heat stresses better than imported breed.

To capture farmers' perceptions about climate change, the survey asked respondents whether they have noticed changes for a set of climate variables now compared with when they were teenagers. The average age of the farmers included in the sample is more than 45 years old. This means that the responses capture changes over at least a period of 30 years. Poultry farmers seem to be more concerned with changes that relate to temperature. In effect, $68 \%$ of the farmers believe that temperature has increased overtime while $45 \%$ expressed concerns for an increase in the length of the heat stress (Table 2). This is aligned with studies that have used long-term climate simulation models to assess temperature trends. Hassan et al. (2013) estimated changes in the normal daily maximum temperature in Nigeria for the warmest month between 2000 and 2050. One of the models predicts an increase of 2 to $2.5^{\circ} \mathrm{C}$ in the North compared with 1.5 to $2{ }^{\circ} \mathrm{C}$ in the South. This is also consistent with studies (e.g., Tambo and Abdoulaye 2013; Ayanlade et al. 2017) that have shown that smallholder farmers in Nigeria have observed increasing temperature in recent decades.

We also inquired whether the same farmers have experienced any loss of product (chicken, eggs) due to weather events such as heat wave. Based on the farmers' responses, we

Table 2 Climate adaptation strategies and farmers' perceptions

\begin{tabular}{lllll}
\hline & $\begin{array}{l}\text { All } \\
\text { Mean }\end{array}$ & Small (T1 $\left.{ }^{\mathrm{a}}\right)$ & Medium (T2) & Large (T3) \\
\hline Use air ventilation (0/1) & 0.045 & 0.042 & 0.062 & 0.163 \\
Use water ventilation (0/1) & 0.003 & 0.000 & 0.016 & 0.147 \\
Pays for litter spreading or decaking or clean out (0/1) & 0.062 & 0.044 & 0.367 & 0.487 \\
Use traditional practices (0/1) & 0.708 & 0.723 & 0.390 & 0.411 \\
Buy medicines (0/1) & 0.127 & 0.102 & 0.543 & 0.752 \\
Buys vitamins (0/1) & 0.292 & 0.277 & 0.507 & 0.723 \\
Have a fish farm (0/1) & 0.009 & 0.004 & 0.089 & 0.153 \\
Use energy efficient bulb (0/1) & 0.078 & 0.070 & 0.160 & 0.334 \\
Average temperature increased (0/1) & 0.682 & 0.701 & 0.323 & 0.292 \\
Length of heat stress is longer (0/1) & 0.451 & 0.460 & 0.250 & 0.297 \\
Experienced loss from weather event (0/1) & 0.100 & 0.100 & 0.180 & 0.190 \\
Number of observations & 1301 & 449 & 428 & 424 \\
\hline
\end{tabular}

a $\mathrm{T} 1, \mathrm{~T} 2$, and T3 refer to farm size (bird holding) terciles where T1 = $0-100$ birds, T2 = $101=1000$ birds, and $\mathrm{T} 3=>1000$ birds. The values have been weighted to be representative of the study regions 
constructed a variable "Experienced loss from weather event", which reflects the impact of weather events on poultry production in our study region. This variable was motivated by the fact that birds are comfortable in temperatures ranging between 10 and $30{ }^{\circ} \mathrm{C}$ and even reduce their feed intake by 3 to $5 \%$ for each additional $1{ }^{\circ} \mathrm{C}$ increase (National Research Council 1981). Thus, understanding how increases in temperature affected farms is important. Ten percent of all farmers responded positively, but this average is masked by differences across farm types. Effectively, close to $20 \%$ of medium and large farms experienced losses related to climate compared with only $10 \%$ of small farms.

\subsection{Determinants of adopting climate change adaptation strategies}

Next, we turn to the determinants of adopting climate change adaptation strategies from the multivariate probit, Poisson, and fractional response models. The variables of interest are farm characteristics (e.g., size of farm), temperature, and farmer characteristics such as farming experience, social networks, and personal experience of loss due to extreme heat.

In Table 3, the results on the determinants of the adoption of adaptation strategies show that farmers who have experienced climate-related losses are more likely to adopt water ventilation, pay for litter spreading, buy medicines and vitamins or use energy efficient bulbs. This is expected since all the above strategies increase the ability of farmers to respond to the negative impacts of extreme heat. On the other hand, exposure to extreme heat discourages investment in a fish farm. This indicates that farms are less likely to invest in building a fish farm on the poultry farm if they have incurred losses in the past.

Experiencing loss due to extreme heat does not influence the adoption of air ventilation and traditional practices. As one would expect, the direction of the effect is negative for the former while it is positive for the latter. Since $70 \%$ of all farmers use traditional practices, one explanation for this finding is that traditional practices are not effective at responding to extreme heat for all the types of farms. Indeed, as variability in temperature (coefficient of variation) increases poultry farmers are less likely to invest in traditional practices; the effect is even more pronounced for larger farms. Air ventilation which includes the use of expensive technologies such as air conditioner (AC) is an important investment just like a fish farm. Greater variability in temperatures promotes the adoption of air ventilation. This suggests that it is an effective strategy already adopted by farmers and as such there is no change in behavior because of climate-induced losses. Overall, these results corroborate a recent finding that production shocks have heterogeneous effects on the adoption of agricultural practices (Gebremariam and Tesfaye 2018).

The results in Table 4 on the determinants of the adoption of multiple adaptation strategies lend credence to the findings above. Both the Poisson and fractional probit response (FPR) models show that on average farmers who have personal experience of loss due to extreme heat are more likely to adopt multiple adaptation strategies. Compared with those who did not experience heat-related losses, those who experienced it are 66.3 percentage points more likely to adopt multiple strategies. Additionally, those who suffered climate induced losses are 9 percentage points more likely to adopt a larger share of adaptation strategies.

The examination of the control variables included in each of the estimations also informs our understanding of the factors that affect the adoption of adaptation strategies. The scale of the farm as proxied by its size may positively or negatively influence adoption depending on the strategy being considered. Overall, increased variability in temperature is associated with a 35-percentage point increase in the adoption of multiple strategies and a 5-percentage point 


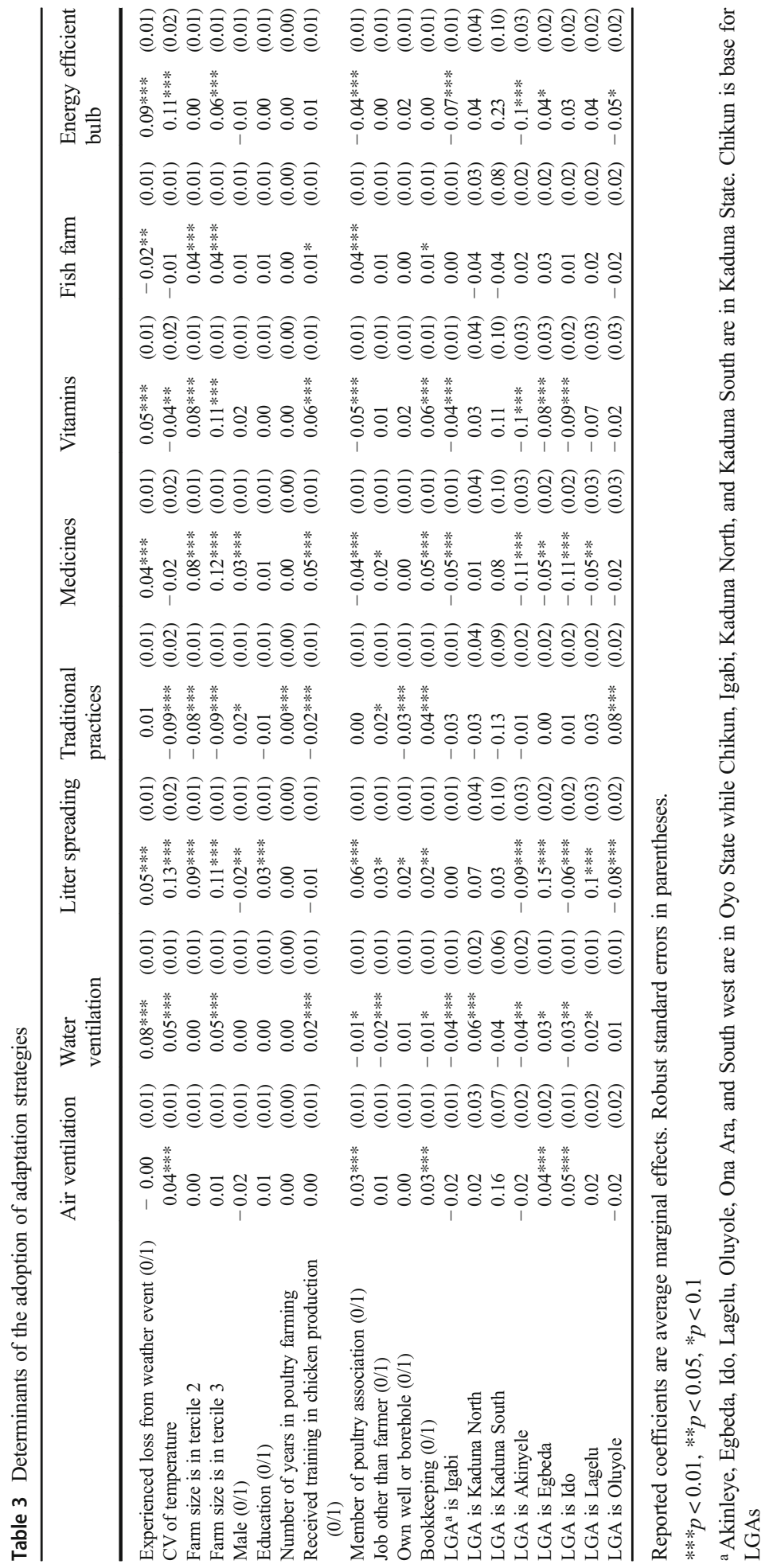


Table 4 Determinants of the adoption of multiple adaptation strategies

\begin{tabular}{|c|c|c|}
\hline & Poisson & Fractional response \\
\hline Experienced loss from weather event $(0 / 1)$ & $0.663 * * *(0.109)$ & $0.090 * * *(0.011)$ \\
\hline $\mathrm{CV}$ of temperature & $0.348 *(0.180)$ & $0.046 * * *(0.013)$ \\
\hline Farm size is in tercile 2 & $0.686^{* * *}(0.136)$ & $0.071 * * *(0.012)$ \\
\hline Farm size is in tercile 3 & $1.114 * * *(0.150)$ & $0.133 * * *(0.014)$ \\
\hline Male $(0 / 1)$ & $0.110(0.130)$ & $0.014(0.012)$ \\
\hline Education $(0 / 1)$ & $0.114(0.156)$ & $0.015(0.013)$ \\
\hline Number of years in poultry farming & $0.004(0.006)$ & $0.001(0.001)$ \\
\hline Received training in chicken production $(0 / 1)$ & $0.287 * * *(0.102)$ & $0.039 * * *(0.010)$ \\
\hline Member of poultry association $(0 / 1)$ & $-0.069(0.118)$ & $-0.009(0.013)$ \\
\hline Job other than farmer $(0 / 1)$ & $0.250(0.160)$ & $0.031 * *(0.015)$ \\
\hline Own well or borehole $(0 / 1)$ & $0.100(0.131)$ & $0.009(0.011)$ \\
\hline Bookkeeping (0/1) & $0.633 * * *(0.110)$ & $0.077 * * *(0.011)$ \\
\hline LGA $^{\mathrm{a}}$ is Igabi & $-0.614 * * *(0.135)$ & $-0.080^{* * *}(0.014)$ \\
\hline LGA is Kaduna North & $0.060(0.352)$ & $0.034(0.031)$ \\
\hline LGA is Kaduna South & $0.715(0.845)$ & $0.111 * * *(0.027)$ \\
\hline LGA is Akinyele & $-1.200 * * *(0.319)$ & $-0.151 * * *(0.034)$ \\
\hline LGA is Egbeda & $0.327(0.244)$ & $0.044 * *(0.018)$ \\
\hline LGA is Ido & $-0.506 * *(0.219)$ & $-0.068 * * *(0.022)$ \\
\hline LGA is Lagelu & $0.191(0.257)$ & $0.028(0.018)$ \\
\hline LGA is Oluyole & $-0.205(0.251)$ & $-0.028(0.020)$ \\
\hline LR Chi Square & $399.55^{* * *}$ & \\
\hline Wald chi square & & $894.57 * * *$ \\
\hline Observations & 1284 & 1284 \\
\hline
\end{tabular}

Reported coefficients are average marginal effects. Robust standard errors in parentheses.

$* * * p<0.01, * * p<0.05, * p<0.1$

a Akinleye, Egbeda, Ido, Lagelu, Oluyole, Ona Ara, and South west are in Oyo state while Chikun, Igabi, Kaduna North, and Kaduna South are in Kaduna State. Chikun is base for LGAs

increase for the adoption of a larger share of strategies. This pattern is, however, not uniform across individual adaptation strategies. For instance, increased variability in temperature is related to a 9-percentage point reduction in the likelihood that poultry farmers will use traditional practices. This is probably because the farmers substitute the traditional practices for modern adaptation techniques such as air and water ventilation, as confirmed by the correlation matrix results in Table 5. There are heterogeneities in farm sizes for the adoption of the strategies considered in this study. As shown in Table 4, compared with small farms, medium, and large farms are about 69 and 111 percentage points more likely to practice any of the strategies, respectively. This shows that the larger the investment, the higher the probability that a farmer invests in adaptation strategies. This is also evident in Table 3 where compared to small farms, medium, and large farms are more likely to adopt water ventilation, pay for litter spreading, buy vitamins and medicines, own a fish farm, and use energy efficient bulbs. This seems to resonate with Zampaligré et al. (2014) finding that herd size is an important determinant of livestock farmers' choice of adaptation strategies as well as Silvestri et al.'s (2012) observation that wealthier livestock farmers are more likely to adapt to climate change.

Additionally, some of the strategies stand out in terms of where they are practiced. This is the case of air ventilation and traditional strategies which have a higher likelihood to be adopted by LGAs located in Oyo state compared with Kaduna state. Oyo state is home to some of the biggest farms in the country which have enough capital to invest in air ventilation, but it also appears to have many small farms given the preponderance of farms practicing traditional 


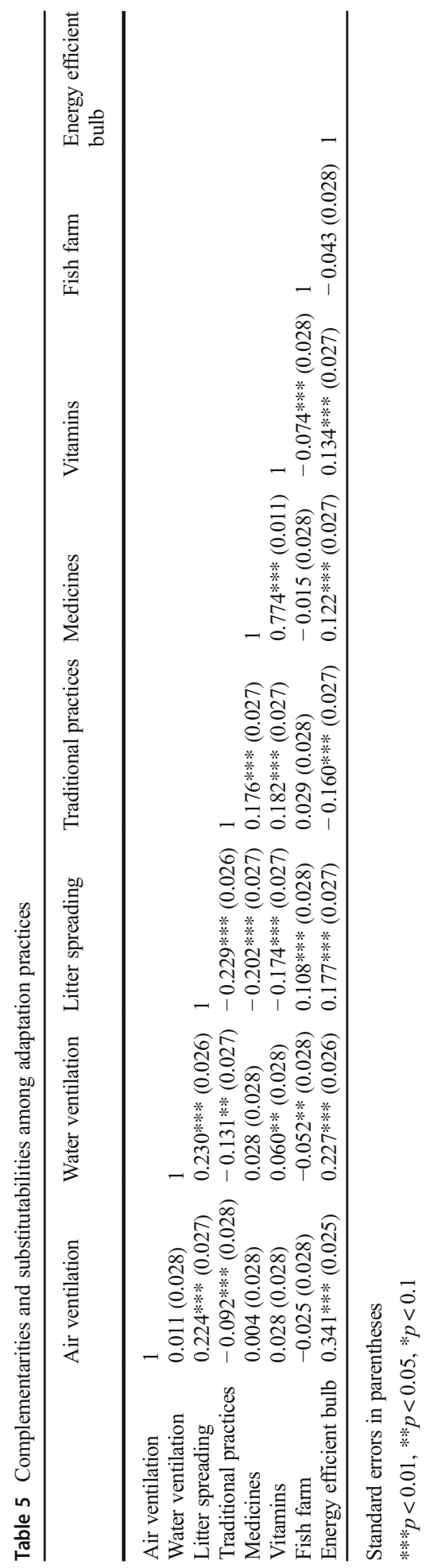


strategies. Moreover, compared with Chikun which is in Kaduna, farmers in Akinleye in Oyo state are 120-percentage points less likely to adopt multiple strategies and $15 \%$ less likely to invest in a large share of strategies.

Experience, access to information (via training) and the level of commercialization (average size of bird holdings) do not affect the probability of adoption in the same way. For instance, the number of years in poultry farming does not affect the probability of adopting multiple strategies. However, farmers who have more experience tend to adopt traditional practices but are wary of investing in energy efficient bulbs and air ventilation. This suggests that it is the new farmers who adopt modern adaptation strategies. This occurrence may also be function of the types of chicken houses that were built in more recent years.

Lastly, membership in a poultry farmer association is associated with a higher likelihood of adopting air ventilation and litter spreading. It also improves the chances that a poultry farm would build a fish pond. As shown in the descriptive statistics, record keeping is more prevailing among the large farms which also tend to be the commercial ones. Farms with financial records are 63 percentage points more likely to invest in multiple adaptation strategies. More specifically, they tend to invest in all the strategies except energy efficient bulbs and are indifferent about water ventilation.

The correlation matrix (Table 5) from the multivariate probit model is also informative, as it indicates the complementarities and trade-offs between the various adaptation strategies. A negative correlation coefficient between two practices suggests that the poultry farmers consider these practices to be substitutes or perceive that one practice is more suitable for adapting to climate change than the other. Conversely, a positive correlation indicates complementarity between the adaptation options. We observe positive correlations between the use of air ventilation, water ventilation, litter spreading, and energy efficient bulbs, suggesting that these modern adaptation practices complement each other. These four adaptation practices are, however, negatively correlated with the use of traditional practices, indicating possible tradeoffs between modern and traditional adaptation practices. Thus, it would be important to understand if particular methods are more effective than others since farmers seem to substitute traditional practices for modern practices (which tend to be complementary), and this might affect the effectiveness of their adaptation. This is important because of the prevalence of distinct adaptation strategies among small and large farms.

\section{Conclusion}

Africa has been identified as a key driver of global meat consumption growth in the next few decades and for which domestic production must play an important role. Poultry production, one of the fastest growing meat subsectors in many countries is threatened by climate events such as heat stress This paper examines the climate change adaptation strategies of poultry farmers in Nigeria. We focus on a set of modern and traditional strategies highlighted by actors along the poultry value chain in Nigeria to be effective at responding to heat stress. We adopt a multivariate probit analysis to explore the determinants of adaptation accounting for the likely correlation in the decision to adopt any one strategy with the decision to adopt other strategies. We supplement this with a Poisson and fractional response models to explore the extent and determinants of adoption of multiple strategies by different kinds of poultry farmers.

Farmers in the study sample are concerned about changes related to temperature as $68 \%$ of them believe that temperature has increased overtime while almost $50 \%$ expressed concerns 
for an increase in the length of the heat stress. Medium and large farms were more likely to report being affected by a loss related to heat stress than small farms. The descriptive analysis indicated that there are heterogeneities in the types of strategies adopted at different scales of operation. The medium and large farms adopt modern strategies while many small farms stick to traditional practices. Regression results on the determinants of the adoption of adaptation strategies confirm this and further reveal that farmers who have experienced climate-related losses are more likely to adopt water ventilation, pay for litter spreading, buy medicines and vitamins, or use energy efficient bulbs. On the other hand, experiencing loss due to extreme heat does not affect the adoption of air ventilation and traditional practices. We further find that on average farmers who have personal experience of loss due to extreme heat are more likely to adopt multiple adaptation strategies at a time.

These findings have important implications for policy makers and practitioners including poultry farmers and extension agents. The fact that the adoption of modern strategies appears limited to medium and large scale farms requires further attention. There is room for innovation as some of the costly strategies such as ventilation adopted by the larger farms can be modified to suit the financial constraints of the small farms. For example, changing water more frequently to keep water cool compared with having a cooling pad or fan. Such strategies should be developed and communicated to farmers. Where modern strategies are inappropriate due to farm size, efforts to breed faster growing more adaptable breeds (as it relates to the tolerance of heat stress) could be helpful.

Given that membership in a poultry farmer association is an important determinant of investment in strategies such as combining poultry production with a fish farm, our findings suggest that medium and large-scale farmers may benefit from efforts that facilitate farmer to farmer learning events across geographic regions. Finally, we find positive synergies between the modern adaptation strategies, and thus policies and programs aiming to promote climate adaptation measures in poultry farming must consider the complementarities between these adaptation strategies.

Acknowledgements The authors acknowledge and appreciate financial support for this work from the United States Agency for International Development (USAID) Nigeria's Feed the Future Nigeria Agricultural Policy Project and MSU AgBio Research. Justice A. Tambo was supported by CABI with core financial support from its member countries (see http:/www.cabi.org/about-cabi/who-we-work-with/key-donors/). We also appreciate inputs and comments from key stakeholders in the Nigerian value chain who participated in the project's rapid reconnaissance as well as in stakeholder workshops in Kaduna and Abeokuta. We appreciate the comments from 2 anonymous reviewers and an editor. Any views expressed or remaining errors are solely the responsibility of the authors.

Open Access This article is distributed under the terms of the Creative Commons Attribution 4.0 International License (http://creativecommons.org/licenses/by/4.0/), which permits unrestricted use, distribution, and reproduction in any medium, provided you give appropriate credit to the original author(s) and the source, provide a link to the Creative Commons license, and indicate if changes were made.

\section{References}

Abatan AA, Osayomi T, Akande SO, Abiodun BJ, Gutowski WJ (2018) Trends in mean and extreme temperatures over Ibadan, Southwest Nigeria. Theor Appl Climatol 131:1261-1272

Adejuwon JO, Odekunle TO (2006) Variability and the severity of the "little dry season" in southwestern Nigeria. J Clim 19:483-493

Aremu O, Bello E, Aganbi B, Festus O (2017) Trend analysis and change point detection of rainfall across the Agro-ecological zones for sustainability development in Nigeria. Environ Risk Assess Remediation 1:36-46 
Ayanlade A, Radeny M, Morton JF (2017) Comparing smallholder farmers' perception of climate change with meteorological data: a case study from southwestern Nigeria. Weather Climate Extremes 15:24-33

Ayanlade A, Radeny M, Akin-Onigbinde AI (2018) Climate variability/change and attitude to adaptation technologies: a pilot study among selected rural farmers' communities in Nigeria. GeoJournal 83:319-331

Bahinipati CS (2015) Determinants of farm-level adaptation diversity to cyclone and flood: insights from a farm household-level survey in eastern India. Water Policy 17(4):742-761

Bhadauria P, Kataria J, Majumdar S, Bhanja S, Divya KG, Kolluri G (2014) Impact of hot climate on poultry production system-a review. J Poult Sci Tech 2(4):56-63

Cappellari L, Jenkins SP (2003) Multivariate probit regression using simulated maximum likelihood. Stata J 3: 278-294

Debela N, Mohammed C, Bridle K, Corkrey R, McNeil D (2015) Perception of climate change and its impact by smallholders in pastoral/agropastoral systems of Borana, South Ethiopia. SpringerPlus 4:236

Dessie T, Getachew F (2016) Shika brown breed. International Livestock Research Institute, Addis Ababa

Fisher M, Snapp S (2014) Smallholder farmers' perceptions of drought risk and adoption of modern maize in southern Malawi. Exp Agric

Gebremariam G, Tesfaye W (2018) The heterogeneous effect of shocks on agricultural innovations adoption: microeconometric evidence from rural Ethiopia. Food Policy 74:154-161

Gous R (2010) Nutritional limitations on growth and development in poultry. Livest Sci 130:25-32

Gregory N (2010) How climatic changes could affect meat quality. Food Res Int 43:1866-1873

Hassan S, Ikuenobe C, Nelson G, Thomas T (2013) Nigeria. In: Jalloh A, Nelson GC, Thomas TS, Zougmoré RB, Roy-Macauley H (eds) West African agriculture and climate change: a comprehensive analysis. IFPRI, Washington, pp 259-290

Heise H, Crisan A, Theuvsen L (2015) The poultry market in Nigeria: market structures and potential for investment in the market. Int Food Agribus Manag Rev 18:197-222

Hitayezu P, Wale E, Ortmann G (2017) Assessing farmers' perceptions about climate change: a double-hurdle approach. Clim Risk Manag 17:123-138

IPCC (2007) Climate change 2007: impacts, adaptation and vulnerability. Contribution of working group II to the fourth assessment report of the intergovernmental panel on climate change. Cambridge University Press, Cambridge

Jones PG, Thornton PK (2009) Croppers to livestock keepers: livelihood transitions to 2050 in Africa due to climate change. Environ Sci Pol 12:427-437

Liverpool-Tasie LSO, Omonona B, Sanou A, Ogunleye W, Padilla S, Reardon TA (2017) Growth and transformation of food systems in Africa: evidence from the poultry value chain in Nigeria. Michigan State University Feed the Future Innovation Lab for Food Security Policy

Massetti E, Mendelsohn R (2018) Measuring climate adaptation: methods and evidence. Rev Environ Econ Policy 12:324-341

Mendelsohn RO, Massetti E (2017) The use of cross-sectional analysis to measure climate impacts on agriculture: theory and evidence. Rev Environ Econ Policy 11(2):280-298

Mulenga BP, Wineman A, Sitko NJ (2017) Climate trends and farmers' perceptions of climate change in Zambia. Environ Manag 59:291-306

National Research Council (1981) Effect of environment on nutrient requirements of domestic animals. National Academy Press, Washington

Nyoni N, Grab S, Archer E (2019) Heat stress and chickens: climate risk effects on rural poultry farming in lowincome countries. Clim Dev 11:83-90

Ou L, Mendelsohn R (2017) An analysis of climate adaptation by livestock farmers in the Asian tropics. Climate Change Economics 8:1740001

PAN (2017) History of the poultry association of Nigeria. Poultry Association of Nigeria, Abuja http://www. poultryassociationng.com/

Parry ML, Rosenzweig C, Iglesias A, Livermore M, Fischer G (2004) Effects of climate change on global food production under SRES emissions and socio-economic scenarios. Glob Environ Chang 14:53-67

Sahel Capital (2015) An assessment of the Nigerian poultry sector (11). Retrieved from Sahel Capital: http://sahelcp.com/wp-content/uploads/2016/12/Sahel-Newsletter-Volume-11.pdf

Seo SN, Mendelsohn R (2008) Measuring impacts and adaptations to climate change: a structural Ricardian model of African livestock management. Agric Econ 38:151-165

Sesmero J, Ricker-Gilbert J, Cook A (2017) How do African farm households respond to changes in current and past weather patterns? A structural panel data analysis from Malawi. Am J Agric Econ 100:115-144

Silvestri S, Bryan E, Ringler C, Herrero M, Okoba B (2012) Climate change perception and adaptation of agropastoral communities in Kenya. Reg Environ Chang 12:791-802

Sonneveld B, Keyzer M, Adegbola P, Pande S (2012) The impact of climate change on crop production in West Africa: an assessment for the Oueme river basin in Benin. Water Resour Manag 26:553-579 
Tambo JA, Abdoulaye T (2013) Smallholder farmers' perceptions of and adaptations to climate change in the Nigerian savanna. Reg Environ Chang 13:375-388

The Economist (2019) Global meat-eating is on the rise, bringing surprising benefits The Economist Magazine, May 4

Thornton PK, van de Steeg J, Notenbaert A, Herrero M (2009) The impacts of climate change on livestock and livestock systems in developing countries: a review of what we know and what we need to know. Agric Syst 101:113-127

United Nations DoEaSA, Population Division (2017) World population prospects: the 2017 revision, Key Findings and Advance Tables

United States Agency for International Development (USAID) 2019. Climate risk in Nigeria. Country risk profile. retrieved from https://reliefweb.int/sites/reliefweb.int/files/resources/2019_USAID-ATLAS-NigeriaClimate-Risk-Profile.pdf

UPA (2007) Urban and peri-urban agriculture in Nigeria, characteristics, challenges and prospects. Policy narratives. Submitted to IWMI-RUAF

Woods BA, Nielsen HØ, Pedersen AB, Kristofersson D (2017) Farmers' perceptions of climate change and their likely responses in Danish agriculture. Land Use Policy 65:109-120

Wooldridge JM (2010) Econometric analysis of cross section and panel data. MIT press, Cambridge

World Fish (2018) WorldFish Nigeria strategy 2018-2-22. Report of World Fish

Zamasiya B, Nyikahadzoi K, Mukamuri BB (2017) Factors influencing smallholder farmers' behavioural intention towards adaptation to climate change in transitional climatic zones: a case study of Hwedza District in Zimbabwe. J Environ Manag 198:233-239

Zampaligré N, Dossa LH, Schlecht E (2014) Climate change and variability: perception and adaptation strategies of pastoralists and agro-pastoralists across different zones of Burkina Faso. Reg Environ Chang 14:769-783

Zhou Y, Staatz J (2016) Projected demand and supply for various foods in West Africa: implications for investments and food policy. Food Policy 61:198-212

Publisher's note Springer Nature remains neutral with regard to jurisdictional claims in published maps and institutional affiliations.

\section{Affiliations}

\section{Lenis Saweda O. Liverpool-Tasie ${ }^{1} \cdot$ Awa Sanou $^{2}$ • Justice A. Tambo ${ }^{3}$}

1 Department of Agricultural, Food and Resource Economics, Michigan State University, East Lansing, MI, USA

2 Department of Community Sustainability, Michigan State University, East Lansing, MI, USA

3 Centre for Agriculture and Biosciences International (CABI), Rue des Grillons 1, 2800 Delémont, Switzerland 